\title{
Saúde e migrações: \\ metodologias participativas como ferramentas de promoção da cidadania
}

Beatriz Padilla $a^{(a)}$

Padilla B. Health and Migration: participative methodologies as tools to promote citizenship. Interface (Botucatu). 2017; 21(61):273-84.

The field of "health and migration" is relatively new, both among health sciences and social sciences, using either traditional quantitative and/or qualitative methodologies. The use of participative methodologies has been an exception although they provide an opportunity for intervention, both with users of health services or with providers. Using an example of research in the field of maternal-child and reproductive health among migrant populations, this paper hopes to contribute to the debate about the use of participative methodologies, their challenges and possibilities as a methodological tool in applying research for social change.

Keywords: Participative methodologies. Maternal and child health. Reproductive health. Immigration.
O campo de estudo "saúde e migrações" é relativamente novo, tanto entre as ciências da saúde como nas ciências sociais, quer a problemática seja abordada com metodologias quantitativas e/ou qualitativas tradicionais. O recurso a metodologias participativas tem sido uma exceção, embora estas ofereçam uma oportunidade concreta de intervenção, quer com os usuários dos serviços de saúde como com os profissionais de saúde. Recorrendo a um caso específico de investigação sobre saúde materno-infantil e reprodutiva nas populações migrantes, este artigo pretende contribuir para o debate sobre o uso dessas metodologias e os desafios e as possibilidades que oferecem como ferramenta metodológica em investigação direcionada à mudança social.

Palavras-chave: Metodologias participativas. Saúde materno-infantil. Saúde reprodutiva. Imigração.

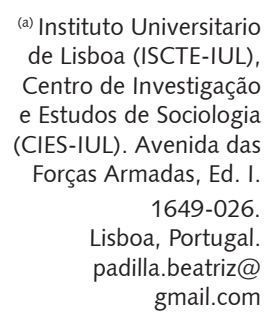

(a) Instituto Universitario de Lisboa (ISCTE-IUL), Centro de Investigação e Estudos de Sociologia (CIES-IUL). Avenida das Forças Armadas, Ed. I. 1649-026. Lisboa, Portugal. padilla.beatriz@ gmail.com 
Embora os estudos migratórios estejam consolidados como uma área do conhecimento interdisciplinar, o campo da 'saúde e migrações' é mais recente. Na Europa, as preocupações iniciais com esta temática surgiram, sobretudo, desde a óptica da saúde pública e da medicina tropical, que frequentemente exotizava os imigrantes como o 'outro' portador de doenças raras, perigosas e contagiosas. O objectivo radicava em saber os riscos associados, e não no bem-estar dessa população.

O interesse das ciências sociais pela temática da saúde e migrações levou a que se desenvolvessem estudos sobre questões mais abrangentes que consideravam os determinantes da saúde e os condicionantes sociais e culturais que ultrapassam o epidemiológico, adoptando uma perspectiva mais humanista, empática e interventiva. Contudo, a tentativa de diálogo entre a biomedicina e a saúde pública com visões holísticas e de integração social ainda está nos seus primórdios.

As primeiras tentativas pretenderam influenciar as políticas públicas, quer as de saúde e bem-estar como as de integração das populações migrantes, cujos resultados são valorizados tanto no plano académico como no político ${ }^{1,2}$. Dias et al. ${ }^{3}$ realizaram um estudo sobre a utilização dos serviços de saúde por parte dos imigrantes, envolvendo os atores implicados (decisores políticos, profissionais de saúde e imigrantes), afirmando que esta abordagem foi enriquecedora e contribuiu para a validação dos dados, bem como para a conscientização sobre a sua pertinência. Estes estudos contribuem para fortalecer a capacidade dos serviços em desenvolverem programas mais adequados às necessidades específicas dessas populações e dos profissionais para lidar com a diversidade 4 .

Com o intuito de influir no policy-making (desenho de medidas políticas), muitos estudos centraram-se na identificação e análise das chamadas boas práticas. Embora não tenham um espírito crítico, a sua ancoragem na intersecção da 'migração e saúde' serve para chamar à atenção para a importância de melhorar o acesso e a acessibilidade aos serviços de saúde.

É na construção deste campo que as metodologias participativas ganham relevância, tanto como ferramenta de recolha de informação como pela possibilidade de envolver os atores-chave, tanto os vinculados à planificação e execução de políticas, como os próprios sujeitos (i.e. imigrantes, mulheres, crianças, etc.).

Qual é a importância das metodologias participativas e colaborativas abrangidas sob o chapéu de uma proposta de investigação-ação? Para respondermos a esta questão, propomos uma breve introdução às metodologias participativas (suas características, pressupostos epistemológicos e ideológicos). e, posteriormente, avançar para o estudo de caso, os desafios enfrentados, e salientando algumas estratégias para melhorar o impacto.

\section{Pressupostos da Investigação-Ação. Família de metodologias}

O desenvolvimento da metodologia de investigação-ação (IA) está associado à tentativa de superar o dualismo entre a teoria e a prática, entre investigadores e investigados ${ }^{5}$. Noffke ${ }^{6}$ agrupa os estudos desenvolvidos em três dimensões: pessoal, profissional e política, embora todas envolvam as três dimensões e estejam inter-relacionadas.

Além da IA, existem outras denominações desta metodologia que destacam as suas muitas nuances: investigação-ação participativa (IAP), investigação colaborativa/cooperativa, investigação participativa, investigação aç̧ão crítica, investigação activista, investigação comprometida, planificação participativa, entre outras. Kemmis e McTaggart referem que a "família da investigação acção" abrange metodologias que incluem tanto a investigação como a aç̧ão, envolvendo sempre um exercício de reflexividade crítica. Estes autores falam também das várias gerações de IA sem esquecer os altos e baixos na sua utilização.

Embora a literatura atribua a Lewin ${ }^{8}$, no âmbito da psicologia social, a primeira sistematização e teorização da investigação acção, a sua aplicação em diferentes contextos e espaços geopolíticos conduziu a diferentes versões. Corey ${ }^{9}$ confere à $I A$ a possibilidade de solucionar problemas no âmbito da educação. Tripp ${ }^{10}$ afirma que é difícil definir a IA: "por duas razões interligadas: primeiro, é um processo tão natural que se apresenta, sob muitos aspectos diferentes; e segundo, ela se desenvolveu de maneira diferente para diferentes aplicações" (p. 445). 
Ainda existem diferenças associadas a questões ideológicas e práticas, que, ao longo do tempo, contribuíram para a sua apreciação positiva ou negativa, às vezes valorizando o seu impacto e capacidade de intervenção na sociedade, e, outras, menosprezando-o por ser percebida como menos rigorosa cientificamente.

Para Lewin ${ }^{8}$, a IA envolve o enfoque experimental por meio da intervenção nos problemas sociais, sendo possível atingir o desenvolvimento teórico e a mudança social. Para Elliot ${ }^{11}$ (p. 69), envolve "o estudo duma situação social com o objectivo de melhorar a qualidade da acção dentro dela própria". Kemmis e McTaggart ${ }^{12}$ aplicam a IA à educação, salientando que é uma indagação autorreflexiva realizada por quem participa (professores, alunos, direcção) em situações sociais para melhorar a racionalidade e a justiça das próprias práticas sociais ou educativas.

Além da aplicação no mundo anglo-saxónico, a IA ganhou reconhecimento nos países em desenvolvimento, especialmente na América Latina, como metodologia não só participativa, mas emancipadora, por estar ancorada na teologia da libertação e na consciência crítica ${ }^{13}$. Assim se entende a definição de IAP proposta por Selener ${ }^{14}$, como "um processo pelo qual membros de um grupo ou uma comunidade oprimida, colectam e analisam informação, e atuam sobre os seus problemas com o propósito de encontrar soluções e promover transformações políticas e sociais" (p. 17).

Nesta geração de IA, a orientação ideológica é mais evidente, associada aos movimentos sociais e à intervenção do investigador na própria comunidade, ou a uma investigação militante ${ }^{15}$.

Balcazar ${ }^{16}$ sugere que, entre os pressupostos ideológicos da IAP, se identifica o papel do investigador: na redução da injustiça social, na promoção da participação dos membros das comunidades na busca de soluções aos problemas, na tentativa de aumentar o controlo sobre as suas vidas (empoderamento). Em consequência, a IAP gera consciência sociopolítica entre os investigadores e entre os membros da comunidade, permitindo o envolvimento de todos no processo de investigação, não meramente como objetos de estudo mas como agentes de mudança. Assim, a IAP permite, por meio da experiência, que os participantes: aprendam a aprender, desenvolvam um olhar crítico, conduzam a investigação e, ainda, comuniquem com grupos semelhantes para conseguirem apoio, valorando o papel que a pesquisa pode ter nas suas vidas e entendendo o seu próprio papel no processo de transformação social de forma empoderadora, e não como vítima.

Existe uma fina linha diferenciadora entre a escola anglo-saxónica e a latinoamericana, mas ambas as visões pretendem a mudança e o envolvimento "empoderador" e "crítico" dos participantes, incluindo o papel ativo do próprio investigador.

\section{Características metodológicas e processuais}

(b) Nesta secção usamos IA ou IAP respeitando a preferência do autor citado. No resto do artigo, para simplificar, optamos por IA
A $\mid A^{(b)}$ como metodologia de pesquisa gera conhecimento de uma forma não tradicional; é um processo de aprendizagem e de recolha de dados em contextos práticos, para serem analisados e interpretados, e, em consequência, actuar sobre a realidade, provocando a mudança social. O objectivo é "aprender através da ação que leva ao desenvolvimento pessoal ou profissional"17 (p. 4). Quase todos os autores descrevem a IA como um processo em espiral de ciclos autorreflexivos ${ }^{7}$ que envolve várias fases pensadas de forma flexível: a) planificação da mudança; b) atuar e observar o processo e as consequências da mudança; c) refletir sobre 
esses processos e consequências; d) replanificar; f) atuar e observar novamente; g) refletir...

Os autores reconhecem que os ciclos em espiral são fáceis de identificar no plano teórico, podendo ser menos claros na prática, existindo a possibilidade de superposições, adaptações e atualizações ao longo do processo, inclusivamente de mudar o rumo. Koshy et al. ${ }^{17}$ recomendam a não aplicação dum modelo demasiado rígido, já que a rigidez pode afectar negativamente o processo, levando a desaproveitar oportunidades únicas. Neste sentido, a sensibilidade e habilidade do investigador são cruciais.

Carr e Kemmis ${ }^{18}$ salientam como principais características: o carácter participativo, o impulso democrático e a contribuição simultânea entre as ciências sociais (conhecimento) e a mudança social (prática). Meyer ${ }^{19}$ explica que a participação exige que os participantes reconheçam a necessidade de mudança e a vontade de ter um papel ativo nessa mudança. Neste sentido os pesquisadores externos que trabalham com as comunidades devem obter a confiança e negociar regras sobre o controle e uso dos dados. O impulso democrático exige que os participantes sejam vistos como iguais, pelo que o investigador é um facilitador da mudança com quem, ao longo do processo, se discutem e validam dados e resultados. Desta forma, o contributo da IA é gerar conhecimento sobre situações específicas, em oposição às triagens clínicas. Kemmis e McTaggart7 identificam outras características da IA, como: o facto de ser prática, colaborativa, emancipatória, crítica, reflexiva e transformadora da teoria e da prática. Para Waterman et al. ${ }^{20}$, a IA nasce da necessidade de se democratizar a investigação, desafiando a institucionalização assente na exclusão, estimulando, ao invés, a participação dos sujeitos excluídos.

Whitelaw et al. ${ }^{21}$, após uma rigorosa revisão de literatura, classificam a IA como: técnica e positivista; colaborativa e interpretativa; crítica e emancipadora. A primeira descrição pretende reduzir o hiato entre teoria e prática, e funciona dentro de uma lógica próxima da investigação tradicional, testando a efetividade duma intervenção concreta. Na segunda tipologia, os investigadores, políticos e profissionais do terreno identificam, conjuntamente, os problemas e visam possíveis soluções; pretendem pôr políticas em prática. A terceira é a verdadeiramente considerada um veículo explícito de expressão política crítica, embora, por estar enraizada ideologicamente, às vezes gere a desconfiança das entidades financiadoras.

A IA em saúde é uma ferramenta crucial porque existe uma preocupação crescente sobre a falta de influência que a evidência empírica tem nas práticas e nas políticas de saúde. Assim, IA poderia ser uma ponte entre a teoria e a prática ${ }^{19}$, demonstrando que a ciência pode e deve estar ao serviço da mudança social.

Depois de expostos os principais aspectos da IA, passamos a uma breve descrição do estudo de caso realizado no contexto das desigualdades e assimetrias em saúde, especificamente sobre a saúde materno-infantil e reprodutiva das populações imigrantes em Portugal.

\section{Saúde e Cidadania: entre a investigação tradicional e a acção}

Na viragem do século XXI, Portugal tornou-se um país de imigração e desenvolveu políticas bemsucedidas na integração dos imigrantes, que o posicionam em segundo lugar a nível internacional, segundo o Índice de Políticas de Integração ou MIPEX ${ }^{22}$ (ferramenta que avalia as políticas de integração dos imigrantes em oito áreas diferentes, usando 167 indicadores www.mipex.eu). No entanto, é no campo da saúde que o desempenho português é inferior, devido à resistência que ainda se verifica no que toca a desenvolver políticas viradas para grupos específicos como os migrantes. $O$ Serviço Nacional de Saúde (SNS) português foi criado em 1979 sob as características da universalidade, sendo tendencialmente gratuito. Em 2001, quando a presença imigrante foi mais visível, o SNS esclareceu melhor a abrangência da universalidade, optando por incluir as populações imigrantes nos cuidados primários, inclusivamente os indocumentados. No entanto, a partir de 2011, devido à crise e com a TROIKA (intervenção do Fundo Monetário Internacional, Banco Central Europeu e Comissão Europeia), a austeridade passou a caracterizar as políticas, condicionando o acesso dos imigrantes aos serviços de saúde, inclusivamente das grávidas e mães ${ }^{1}$. Neste contexto, aprofundar os conhecimentos sobre as necessidades não satisfeitas no âmbito da saúde materno-infantil e reprodutiva entre as 
populações migrantes, tornou-se indispensável tanto a nível teórico como da intervenção.

Em resposta à lacuna no levantamento destas necessidades, decorreu o projecto "Saúde e cidadania: disparidades e necessidades interculturais na atenção sanitária às mães imigrantes", financiado pela Fundação para a Ciência e a Tecnologia de Portugal, entre 2011 e 2014, nas Áreas Metropolitanas de Lisboa e Porto. No presente artigo, será focado apenas o caso da Área Metropolitana de Lisboa (AML). A metodologia escolhida foi qualitativa e interdisciplinar, combinando vários métodos de recolha de dados: entrevistas a informantes-chave (profissionais de saúde, assistentes sociais, mediadores culturais, associações, líderes comunitários, entre outros); observação participante em centros de saúde e outras entidades que prestavam serviços de saúde a grávidas, mulheres e crianças; estudos de caso (acompanhamento pormenorizado de algumas mulheres imigrantes grávidas); entrevistas em profundidade com grávidas e mulheres imigrantes com crianças; atividades de intervenção com grupos de mulheres imigrantes; e realização de um fórum comunitário e a construção de alianças comunitárias. Em relação à avaliação de necessidades, o projecto beneficiou dos resultados obtidos num outro projecto "Meeting the healthcare needs of culturally diverse populations: A psycho-social approach to cultural competences in health professionals" (Marie Curie Actions FP7-People-2010-IEF). A Tabela 1 detalha as entrevistas realizadas.

\begin{tabular}{llr}
\multicolumn{1}{c}{ Tabela 1. Entrevistas } & \\
\hline \multicolumn{1}{c}{ População-alvo } & \multicolumn{1}{c}{ Atores } & N \\
\hline Mulheres & & 65 \\
& Grávidas & 15 \\
& Mães com crianças & 46 \\
Prof. Saúde & Mulheres sem filhos & 4 \\
& & 80 \\
& Médicos & 25 \\
& Enfermeiros & 30 \\
& Assistentes sociais & 22 \\
Estado \& Soc Civil & 3 \\
& Mediadores culturais & 40 \\
& & 21 \\
& ONGs & 1 \\
& Agências de governo & 3 \\
& Municípios & 2 \\
Total & Org. profissionais & 10 \\
& Inst. educativas & 3 \\
& Outros & 185 \\
\hline
\end{tabular}

As participantes residiam em bairros localizados na $A M L$, caracterizados pela presença significativa de imigrantes e com fragilidades socioeconómicas. As imigrantes eram maioritariamente originárias dos Países Africanos de Língua Oficial Portuguesa (PALOPs) ou descendentes e do Brasil, embora também tenham sido entrevistadas algumas mulheres portuguesas, incluindo algumas de etnia cigana.

O projeto procurou desvelar como as mulheres imigrantes efetivavam a cidadania em saúde, como um primeiro passo para exercer a cidadania. Definimos cidadania em saúde como o crescente envolvimento das cidadãs em assumirem responsabilidades em saúde, tomando decisões informadas. Os principais objectivos incluíram:

1- Conhecer as necessidades das mulheres imigrantes e autóctones no que concerne ao acesso e à qualidade da saúde materno-infantil e reprodutiva.

2- Identificar barreiras ao acesso e à utilização dos serviços de saúde. 
3- Comparar as percepções das imigrantes relativamente à qualidade e adequação do serviços de saúde recebidos com a percepção dos profissionais de saúde que prestam esses cuidados.

4- Identificar boas práticas com vista a desenvolver ferramentas interculturais e modelos de ação passíveis de aplicação noutros contextos.

5- Conhecer a acessibilidade das imigrantes aos serviços de planificação familiar e de interrupção voluntária da gravidez (IVG).

6- Adoptar uma abordagem de investigação-ação, visando promover a cidadania em saúde.

7- Facilitar o desenvolvimento duma aliança comunitária com a sociedade civil e o sistema de saúde, de modo a dar continuidade ao trabalho.

Alguns elementos influenciaram o modo como a IA foi realizada: ter sido desenvolvido desde um centro de investigação de universidade pública portuguesa (e não numa comunidade, entidade de saúde ou da sociedade civil); a equipa ser interdisciplinar (como elementos oriundos das ciências sociais - sociologia, antropologia, psicologia social - e não das ciências da saúde), e, ainda, a maioria das investigadores serem de origem imigrante (mas não africanas); o facto de o sistema de saúde português ser excessivamente formal, pouco flexível, hierárquico e focado em questões biomédicas; e o combinar metodologias qualitativas tradicionais (entrevistas, observação participante, etc.) com a IA.

A IA envolveu duas estratégias de intervenção diferenciadas. Por um lado, a intervenção com as mulheres (imigrantes, não imigrantes, grávidas e com filhos pequenos), e, por outro, a intervenção com profissionais de saúde e sociedade civil com vista a constituir uma aliança comunitária. Neste sentido, o ethos do projeto assentava num compromisso com a realidade visando a transformação social.

$\mathrm{O}$ desenho articulou duas partes. A primeira abrangeu os objectivos 1 a 5, visando que a recolha de informação permitisse: um diagnóstico ou avaliação das necessidades de saúde satisfeitas e não satisfeitas, das barreiras de acesso aos serviços, a identificação das estratégias desenvolvidas (mulheres, profissionais de saúde, sociedade civil) na resolução de problemas. Também contrastamos a opinião e as percepções das mulheres e dos profissionais de saúde, porque este cruzamento seria relevante no momento da IA. A segunda parte abarcou os objectivos 6 e 7, desenvolvidos a partir dos resultados da primeira etapa (mapeamento de problemáticas e recursos existentes e em falta) nos vários contextos da AML para realizar intervenções apropriadas.

\section{Intervenção no terreno: passando à ação}

Os resultados preliminares obtidos na primeira etapa (diagnóstico) moldaram as intervenções, tanto as realizadas com as mulheres imigrantes como o próprio processo de construção da aliança comunitária e a realização do Fórum Comunitário.

Nas intervenções com as mulheres, a pesquisa inicial permitiu identificar a existência de variados projetos de intervenção em saúde e de recursos distribuídos de forma desigual no território, o que foi levado em consideração no momento de decidir as intervenções (onde, como e porquê). Alguns municípios eram abrangidos por muitas iniciativas, e noutros pouco ou nada. Dado que o objectivo não era concorrer com projetos em curso, a opção foi desenvolver intervenções em parceria com a sociedade civil, onde fossem pertinentes e significassem uma mais-valia para as mães. Dos vários territórios, selecionamos dois com escassos recursos (Cacém em Sintra e Unhos em Loures), e organizamos uma intervenção em cada um.

A primeira foi um workshop de formação com mães jovens de origem imigrante (maioritariamente cabo-verdiana) sobre alimentação e nutrição e saúde do bebé (temática escolhida pelas interessadas). Liderado por uma médica imigrante, envolveu jogos didáticos (como preparar uma refeição nutritiva com poucos recursos) e uma sessão aberta de perguntas. As pesquisadoras cuidavam/brincavam com as crianças e/ou realizavam observação participante. Na medida do possível, as relações se mantiveram horizontais num ambiente descontraído. As mães se mostraram satisfeitas por terem recebido novas informações para tomarem melhores decisões acerca da saúde familiar.

A segunda intervenção foi a celebração do Dia da Mãe, com grávidas e mães, num encontro que contemplava formação para elas e atividades lúdicas para os filhos. Neste caso, além da equipa de investigação como observadoras participantes, participou uma equipa interdisciplinar de especialistas 
(médica e odontóloga, ambas imigrantes, e uma professora de yoga), que lideraram sessões formativas sobre: saúde na gravidez, a amamentação, a nutrição e a saúde oral (grave problema entre as grávidas e lactantes devido aos poucos serviços disponíveis) e uma aula de yoga sobre respiração, relaxamento e massagens para mães e bebés. No fim, foram entregues enxovais para os bebés, roupas para crianças e para grávidas, carrinhos para bebés, brinquedos e produtos para a saúde oral. Estes elementos foram angariados pela equipa numa campanha divulgada nas universidades e entre amigos, durante os meses anteriores. A parte formativa do evento envolveu perguntas e respostas, discussão de exemplos e exercícios, mas o encontro foi também uma oportunidade para as mulheres se conhecerem, partilharem experiências e ativar uma incipiente rede de entre-ajuda.

A segunda estratégia participativa foi o desenvolvimento duma aliança comunitária, que se prolongou ao longo do projeto, fazendo a ponte entre a recolha de informação e a ação. Desde as entrevistas iniciais realizadas a médicos/as, enfermeiros/as, assistentes sociais, psicólogos/as, mediadores culturais e técnicos/as das associações, a equipa anunciou que um dos objectivos abarcava a intervenção, pelo que numa etapa posterior seriam convidados a participar e refletir com outros atores para, conjuntamente, articularem uma aliança comunitária ao nível da AML. Esta proposta foi recebida de forma positiva e ajudou a realizar um mapeamento dos recursos, programas e práticas existentes.

Posteriormente, estes atores, o Alto Comissariado para a Imigração e o Dialogo Intercultural, vários Centros de Saúde, ONGs e alguns académicos especialistas foram convidados a participar do Fórum Comunitário. Este visou uma estratégia de participação direcionada, promovendo o diálogo entre os participantes de modo a se conhecerem e darem continuidade ao trabalho. De manhã, apresentou-se o projeto seguido de partilha de experiências com o intuito de preparar o terreno para as seguintes atividades. Na parte da tarde, os participantes optaram por se envolverem em um dos três workshop previstos, que aprofundaram o debate sobre os temas identificados como mais relevantes na avaliação de necessidades (Quadro 1).

Quadro 1. Workshops do Fórum Comunitário

\begin{tabular}{|l|l|}
\hline Workshop 1 & Relacionamento entre profissionais da saúde e utentes: o diálogo possível \\
\hline Workshop 2 & Influências dos factores socioeconómicos no acesso à saúde \\
\hline Workshop 3 & O empowerment das mulheres nas suas comunidades \\
\hline
\end{tabular}

Cada workshop teve um moderador externo, de modo a permitir que a equipa de investigação estivesse focada na observação participante. O encerramento do Fórum envolveu uma sessão de partilha de conclusões por cada workshop, fechando o evento com a participação de um grupo de jovens do teatro fórum, interpretando uma peça sobre a gravidez na adolescência na comunidade cabo-verdiana.

Um dos objectivos do Fórum Comunitário era facilitar o encontro dos diferentes atores para integrarem a aliança comunitária; e outro objectivo foi o estimular a participação e discussão com vista a construir de forma conjunta as conclusões do projeto. Devido à participação fluída dos envolvidos, à riqueza na discussão e no intercâmbio, o balanço do Fórum foi positivo.

O Quadro 2 sintetiza as estratégias usadas na IA segundo a população-alvo e o tipo de intervenção.

Quadro 2. IA no Projeto Saúde e Cidadania

\begin{tabular}{|c|c|}
\hline \multicolumn{2}{|c|}{ Estratégias Participativas (IA) } \\
\hline Mulheres & Profissionais Saúde, ONGs, SNS \\
\hline - Workshop Formação & - Aliança Comunitária \\
- Ação Dia da Mãe & - Fórum Comunitário \\
\hline
\end{tabular}


Neste artigo, o objectivo é analisar, de forma crítica, a IA como metodologia participativa, pelo que não é pertinente a apresentação dos resultados do projeto. Passamos, por isso, à reflexão crítica, referenciado alguns dos desafios e potencialidades da metodologia.

\section{Reflexão crítica sobre a IA em migrações e saúde}

Globalmente, a experiência de IA foi positiva, mas vários ângulos merecem ponderação e reflexão. Para uma melhor apreciação, dividimos os assuntos em: a) desenho da investigação e os ciclos da IA; b) propósito da IA; c) características da IA; d) condicionantes relevantes na realização deste estudo.

a) Desenho e ciclos da IA

Devido ao facto de o projecto Saúde e Cidadania ter sido desenvolvido por um centro de investigação duma universidade, e não por instituição comunitária, sentimos que esta situação condicionou o delineamento da IA, existindo uma diferença entre a forma ideal de conceber uma $I A$, especialmente nas etapas de desenho - que deve promover a participação - e as possibilidades concretas de realização na prática. Vários elementos interferem. Por exemplo, a necessidade de obter financiamento limita a IA em vários sentidos. O tempo para conceber o projecto é geralmente reduzido, e nem sempre é possível contar com todos os apoios comunitários desejáveis, nem envolver as entidades públicas do âmbito da saúde (as autorizações são morosas) ou, mesmo, de outras entidades relevantes. Os possíveis parceiros, como as ONGs, nem sempre mostram interesse nas fases de candidaturas porque supõem dedicação, sabendo à partida que as possibilidades de aprovação são limitadas. Ainda, dependendo das regulamentações dos concursos e financiamento, alguns não possibilitam as associações terem orçamentos, aumentando o desinteresse. Por outro lado, entre algumas entidades da sociedade civil existe resistência em acreditar no compromisso sincero da academia com a realidade comunitária ou medo de serem considerados só "objectos de estudo". As equipas devem desenvolver e melhorar as relações com as entidades parceiras, antes de pensarem em candidaturas. Além das desconfianças entre equipas científicas e entidades comunitárias, quando estas são resolvidas, muitas vezes, é preciso persuadir os avaliadores dos projetos de investigação da importância e relevância das metodologias participativas como opções válidas para avançar no conhecimento e mudar a realidade, especialmente com certas populações.

O projeto Saúde e Cidadania foi concebido sob num ethos de inclusão social, abrangendo uma população vulnerável (mulheres grávidas e mães imigrantes), pelo que a IA apresentou-se como uma metodologia adequada, especialmente pela potencialidade como ferramenta de recolha de dados e, em consequência, melhorar o tipo de conhecimento recolhido, bem como pela possibilidade de intervir sobre essa realidade. Na prática, a inclusão inicial de todos os parceiros não foi possível, pelo que a IA não foi desenhada com o consentimento expresso das futuras entidades envolvidas quer devido aos morosos processos de autorização de algumas, quer devido à falta de compromisso na fase inicial. No entanto, uma vez que o diagnóstico era uma etapa central para conhecer as necessidades de saúde das grávidas e das mulheres imigrantes, seria possível identificar parceiros posteriormente, assumindo uma maior participação da comunidade oprimida (usando a caracterização de Seliner).

Em relação à aplicabilidade do modelo da IA em forma de espiral repetitiva, os projectos de investigação académicos nem sempre permitem repetições em passos subsequentes. Por exemplo, os prazos a cumprir nas etapas planificadas podem não coincidir com a disponibilidade dos outros actores ou parceiros envolvidos, ou com o timing das comunidades. Normalmente, é possível uma primeira aplicação, que pode ser pensada como piloto, mas as etapas posteriores, que corrigem e melhoram as ações ou intervenções iniciais, geralmente ficam como propostas futuras. No projeto Saúde e Cidadania, a sua natureza não possibilitava repetições em espiral, pelo que foram oportunidades únicas de transformação (via formação participativa), em especial, no caso das intervenções com as mulheres na aliança comunitária. Devido às limitações em termos de tempo, não foi possível realizar novamente as iniciativas melhoradas. No entanto, tal não impediu uma aprendizagem transversal sobre a forma de realizar as ações com as participantes. Do primeiro evento com as jovens mães, foi possível retirar alguns ensinamentos para o segundo evento, embora tenha sido realizado com outro grupo de mães. 
Quanto à construção de aliança comunitária, o Fórum também não foi repetido, mas a construção da própria aliança foi conseguida ao longo do tempo. O Fórum foi um dos resultados delimitados temporalmente, mas com a possibilidade de continuação no futuro, embora tal já não dependesse da equipa de investigação.

b) Propósito da IA

Quanto à tentativa da IA de melhorar as práticas, o projecto, por meio dos vários métodos de recolha e nas intervenções, identificou barreiras na efetivação da cidadania em saúde das mulheres imigrantes. Nesse sentido, e na medida do possível, proporcionou conhecimentos que pudessem ajudar a melhorar o acesso e a acessibilidade aos serviços de saúde, quer a nível individual, com a mulheres imigrantes nos momentos das intervenções, quer a nível comunitário e do SNS, com a aliança comunitária e o Fórum na AML. No entanto, o impacto nesta segunda instância é limitado, dado que a equipa não contava com o poder necessário para mudar o SNS. Contudo, os esforços foram canalizados a Direção-Geral de Saúde e para o Alto-Comissariado para a Imigração e Diálogo Intercultural (ACIDI, nesse momento), e, também, promovidos por meio da disseminação de resultados ao público, decisores e autoridades responsáveis no âmbito da saúde. Ao todo, a desejada mudança social ficou limitada ao grupo de mulheres e aos profissionais e ONGs que participaram, sem podermos avaliar, ao certo, o impacto real, especialmente na vida das mulheres imigrantes envolvidas.

c) Caraterísticas da IA

Como mencionado, as características fundamentais da IA ${ }^{23}$ envolvem: o carácter participativo, o impulso democrático e a contribuição simultânea entre a investigação e a ação. O projeto envolveu a participação de vários tipos de atores, mas houve momentos de maior e menor participação. A necessidade de transformação social nem sempre foi evidente para estes atores (mulheres, profissionais da saúde, ONGs), não por falta de vontade mas por não estarem cientes da possibilidade de assumirem um papel ativo nessa transformação. No caso das imigrantes que participaram nas intervenções, algumas assumiram um papel ativo como cidadãs, traduzido numa atitude favorável na criação de redes entre-ajuda e perante os conhecimentos adquiridos. Mas outras participaram, sobretudo, na expectativa de obteren algo em troca (roupas, brinquedos, enxoval). Do lado dos profissionais da saúde e sociedade civil envolvidos no Fórum Comunitário, a vontade de envolvimento a favor da mudança era manifesta, no entanto, a capacidade de exercer poder efetivo (melhorar o acesso e a acessibilidade aos cuidados de saúde) dependia de fatores externos (posição que ocupavam, capacidade de mobilização). Contudo, dado que, no Fórum, participaram autoridades do Ministério da Saúde, a mensagem sobre a necessidade de mudança e em que aspectos, foi passada.

Segundo Meyer ${ }^{19}$, a participação envolve também confiança em relação à equipa de investigação. Estabelecer estes laços foi mais fácil com as associações, e mais restrito com as entidades do âmbito da saúde, como os Agrupamentos de Centros de Saúde (ACES) e a Administração Regional de Saúde, e no contato direto com as mulheres imigrantes. As entidades públicas exigiram autorizações de ética para entrevistarem os profissionais de saúde, condicionando a sua própria participação, possivelmente por medo dos resultados no contexto da crise financeira e cortes orçamentais que afectaram significativamente o acesso e a acessibilidade aos cuidados de saúde por parte das imigrantes. Por outro lado, a equipa dependeu das ONGs na identificação das mulheres envolvidas, pelo que a empatia e a capacidade de escuta foram a forma de ganhar a confiança. A boa relação estabelecida permitiu a realização dos acompanhamentos (estudos de caso) quando elas precisaram de apoio para irem ao médico ou realizarem exames (ecografias, consultas, etc.), ou procuravam outros serviços (polícia de fronteira, ONGs, etc.) para resolverem os seus problemas. Estas relações de confiança foram também uma oportunidade de intercâmbio e mobilização para ambas as partes.

A dimensão relacionada com o impulso democrático da IA que considera todos os participantes como iguais, foi possível de forma relativa. A equipa tratou os participantes (mulheres, ONGs, profissionais de saúde) em pé de igualdade, no entanto o sentimento de desigualdade nas relações, especialmente com as imigrantes, esteve presente, dependendo do contexto, do ambiente nas relações interpessoais, entre outros. A própria equipa de investigação estava integrada por pesquisadoras (professoras, pós-doutorandas e estudantes de doutoramento), e não por membros da comunidade, situação difícil de contornar mas que teve um peso negativo nas relações horizontais. Por outro lado, a 
equipa não era uma intermediária no sentido lato, dado que dependia das parcerias com as ONGs para estabelecer contato direto com as imigrantes, situação que não favoreceu a discussão e validação do conhecimento, salvo em determinadas ocasiões.

Sobre a terceira característica, a contribuição simultânea entre investigação e a ação, por meio das ações do projeto (intervenções, fórum comunitário) tentamos exercer influência, no entanto seria exagerado afirmar que houve uma transformação profunda da realidade. O sucesso foi mais visível na tentativa de uma maior conscientização de todos os atores envolvidos e na chamada de atenção pública para a degradação evidente do SNS no acesso e acessibilidade aos cuidados de saúde materno-infantil e de saúde reprodutiva, especialmente entre as populações imigrantes, contrariando o discurso oficial desatualizado sobre a existência de acesso universal, incluindo das mulheres imigrantes documentadas ou indocumentadas, à saúde materno-infantil.

d) Condicionantes

Um conjunto de fatores tiveram um papel importante no projeto e nos resultados, dado que o seu início coincidiu com o agravamento da crise económica em Portugal, marcado pela austeridade e cortes orçamentais que tiveram um impacto negativo na saúde das imigrantes, nomeadamente as indocumentadas. Neste sentido, presenciamos a desarticulação de redes sociais de apoio e a resiliência na procura de soluções, situação que afetou as relações com o SNS.

Um segundo condicionante na relação com o SNS teve a ver com a formação da própria equipa de investigação, composta por pesquisadoras das ciências sociais, e não das ciências da saúde. Os profissionais de saúde em Portugal, especialmente os médicos, por estarem acostumados a realizar estudos clínicos, epidemiológicos e biomédicos, desconfiam dos estudos qualitativos como o nosso, o que dificultou o processo de pedido formal de autorização à comissão de ética. No entanto, dentro do SNS, deparámo-nos com duas posições contraditórias que ilustram os interesses opostos dentro do próprio sistema. Enquanto os profissionais inseridos nas comunidades, especialmente enfermeiros/ as, queriam participar para mudar a situação, os Diretores e responsáveis de serviço exibiam apatia e colocavam entraves, situação que desfavoreceu o trabalho da aliança comunitária.

Um terceiro aspecto, de teor reflexivo, é a importância de não se perder a perspectiva global do projeto quanto à transformação social pretendida com a IA. A desejável a mudança no plano individual das imigrantes por meio de intervenções empoderadoras, como aquelas trazidas pela aliança comunitária, daí que manter o balanço entre ambas - perspetiva individual (mulheres) e global (objectivo de mudança a nível macro) - fosse um desafio. Num momento de hesitação sobre a capacidade de 'fazer a diferença', um grupo de profissionais da saúde confidenciou que o projeto tinha tido um impacto positivo por ter criado um espaço de reflexão. Este reconhecimento deu um novo ímpeto ao trabalho de intervenção.

\section{Palavras finais}

A experiência de IA no projeto Saúde e Cidadania aponta para o facto de que benefícios deste tipo de método superam as fragilidades do mesmo, podendo estas serem ultrapassadas com criatividade, persistência e flexibilidade. Os resultados positivos abrangeram tanto as imigrantes como os profissionais de saúde e a sociedade civil interessados na transformação social.

De uma perspetiva académica, é importante manter uma mente aberta em relação aos objectivos possíveis de atingir, reconhecendo tanto constrangimentos como mais-valias. A incorporação da IA na pesquisa permitiu-nos fazer uma recolha sistemática de dados, de forma participativa e consensual, que serviram para complementar diagnósticos e avaliações de necessidades sobre o acesso das imigrantes aos serviços de saúde materno-infantil e reprodutiva. Deste modo, a IA como ferramenta complementar ajudou a planificar a ação, unindo investigação e prática e possibilitando, em parte, a sua incorporação no planeamento das políticas públicas.

Quanto aos tipos de IA identificados ${ }^{21}$, o nosso projeto não assumiu unicamente uma das tipologias, mas devido à sua dupla intervenção (imigrantes e profissionais de saúde/sociedade civil), incorporou características de todas elas ao recolher dados sistematicamente, interpretá-los em colaboração com os profissionais de saúde e adotar uma perspetiva crítica com visão empoderadora. 
Os resultados do projeto revelam a riqueza da IA como metodologia autónoma e complementar, porque, além de promover a mudança por meio da intervenção, permite a recolha de informações relevantes não disponíveis por outras vias. A IA, pelo facto de promover a adopção de perspectivas críticas e reflexivas, que geram consciência crítica nas e sobre as populações envolvidas (i.e. imigrantes, profissionais de saúde, sociedade civil), impulsionou que as próprias participantes assumissem um papel ativo na identificação de problemas e soluções. O resultado aponta para a IA como metodologia promissória para abordar temáticas na intersecção da saúde, migrações e género, permitindo conferir novas orientações a problemáticas geralmente abordadas pelas ciências da saúde com enfoques epidemiológico e biomédico.

As equipas de pesquisa de IA devem ser interdisciplinares das ciências sociais e da saúde, quer para integrarem as várias perspectivas quer para desenvolverem uma visão holística sobre os serviços e as necessidades de saúde das populações vulneráveis. Para a IA ter mais impacto, é preciso que as equipas integrem, via parcerias, elementos da sociedade civil e entidades estatais no âmbito da saúde, de modo a ter representado o leque de atores e de assegurar influência a nível das políticas. A complementaridade de olhares, perspectivas e atores na IA pode significar mudanças sociais mais profundas e douradoras nas comunidades, tornando-se uma ferramenta de promoção da cidadania, inclusivamente entre populações imigrantes, geralmente excluídas dessa cidadania.

Finalmente, a IA dever ser entendida como uma estratégia relevante na investigação realizada nas universidades, porque, por meio da ligação teoria-prática, a universidade assume um papel comprometido dentro do que hoje se denomina investigação responsável, "devolvendo" às comunidades o conhecimento recebido.

\section{Referências}

1. Padilla $B$, Hernández-Plaza $S$, Ortiz A. Avaliando as boas práticas em saúde e migrações em Portugal: teoria, prática e política. Forum Sociol. 2012; 22:33-41.

2. Padilla B, Hernández-Plaza S, Freitas C, Masanet E, Santinho C, Ortiz A. Cidadania e diversidade em saúde: necessidades e estratégias de promoção de equidade nos cuidados. Saude Tecnol. 2013; Supl:57-64.

3. Dias S, Rodrigues R, Silva AC, Horta R, Cargaleiro H. Procura de cuidados e acesso aos serviços de saúde em comunidades imigrantes: um estudo com imigrantes e profissionais de saúde. Arq Med. 2010; 24(6):253-9.

4. Dias S, Gama A. Investigação participativa baseada na comunidade em saúde pública: potencialidades e desafios. Rev Panam Salud Publica. 2014; 35(2):150-4.

5. Noffke S, Somekh B, organizadores. Handbook of educational action research. London: Sage; 2010. p. 1-5.

6. Noffke S. Revisiting the professional, personal and political dimensions of action research. In: Noffke S, Somekh B. Handbook of educational action research. London: Sage; 2010. p. 6-23.

7. Kemmis S, McTaggart R. Participatory action research: communicative action and the public sphere. In: Denzin NK, Lincoln YS. Strategies of qualitative inquiry. 3a ed. Thousand Oaks: Sage; 2007. p. 271-330. 
8. Lewin K. Action research and minority problems. J Soc Issues. 1946; 2(4):34-46.

9. Corey SM. Action research to improve school practices. New York: Columbia University, Teachers College Press; 1953.

10. Tripp D. Pesquisa ação: uma introdução metodológica. Educ Pesqui. 2005; 31(3):443-66.

11. Elliot J. Action Research of educational change. Philadelphia: Open University Press; 1991.

12. Kemmis S, McTaggart R. The action research planner. 3a ed. Victoria: Deakin University; 1988.

13. Freire P. Pedagogy of the oppressed. New York: Continuum; 1970.

14. Selener D. Participatory action research and social change: approaches and critique. New York: Cornell University; 1997.

15. Borda OF. Conocimiento y poder popular. Bogotá: Siglo XXI; 1985.

16. Balcazar FE. Investigación acción participativa (iap): aspectos conceptuales y dificultades de implementación. Fundam Humanid. 2003; 27:59-77.

17. Koshy E, Waterman H, Koshy V. Action research in healthcare. Los Angeles: Sage; 2011.

18. Carr W, Kemmis S. Becoming critical: education, knowledge and action research. London: Falmer; 1986.

19. Meyer J. Qualitative research in health care: using qualitative methods in health related action research. Br Med J. 2000, 32(7228):178-81.

20. Waterman $H$, Tillen $D$, Dickson $R$, de Koning K. Action research: a systematic review and guidance for assessment. Health Technol Assess. 2001; 5(23):1-166.

21. Whitelaw S, Beattie A, Balogh R, Watson J. A review of the nature of action research. Cardiff: Welsh Assembly Government; 2003.

22. Huddleston T, Bilgili O, Joki A, Vankova Z. Migrant Integration Policy Index 2015. Barcelona, Brussels: CIDOB and MPG; 2015.

23. Meyer J. Action research. In: Gerrish K, Lacey A, organizadores. The research process in nursing. Oxford: Blackwell; 2006.

Padilla B. Salud y migraciones: metodologías participativas como herramientas de promoción de la ciudadanía. Interface (Botucatu). 2017; 21(61):273-84.

El campo de estudio "salud y migraciones" es relativamente nuevo, tanto entre las ciencias de la salud como en las ciencias sociales, tanto si la problemática es abordada con metodologías cuantitativas y/o con metodologías cualitativas tradicionales. Recurrir a metodologías participativas ha sido una excepción, aunque ellas ofrezcan una oportunidad concreta de intervención, tanto con los usuarios de los servicios de salud como con los profesionales de salud. Recurriendo a un caso específico de investigación sobre salud materno-infantil y reproductiva en las poblaciones migrantes, este artículo pretende contribuir al debate sobre el uso de estas metodologías y los desafíos y las posibilidades que ofrecen como herramienta metodológica en investigación dirigida al cambio social.

Palabras-clave: Metodologías participativas. Salud materno-infantil. Salud reproductiva. Inmigración.

Submetido em 01/08/2016. Aprovado em 11/12/2016 